\title{
NOTES ON THE REDACTED FRAGMENTS OF LIDAI FABAO JI, AN EARLY CHAN BUDDHIST CHRONICLE ${ }^{*}$
}

\author{
SUN JIANQIANG \\ Centre for the Study of Religion, Leiden University \\ P.O. Box 9515, NL-2300 RA Leiden, the Netherlands \\ e-mail: j.sun@hum.leidenuniv.nl
}

Thirteen ancient Chinese manuscripts have been seen as texts of a long lost 8th-century early Chan Buddhist chronicle, the Lidai fabao ji. A number of textual indications, however, suggest that they cannot be taken as the Tang sources, because their texts have been redacted between 907 and the early 11 th century. The original Tang source, Lidai fabao ji, remains mysterious to date.

Key words: The Lidai fabao ji, early Chan Buddhism, the Tang dynasty, redacted manuscripts.

Recently, thirteen ancient Chinese manuscripts have received a considerable amount of consideration. These fragments, it is said, are the original texts of an elusive 8thcentury Chan Buddhist chronicle, the Lidai fabao ji 歷代法寶記. ${ }^{1}$ Since it describes the Baotang School 保唐宗 of today’s Sichuan, a province in Southwest China, especially the history of this particular school, this chronicle, it is assumed, preserves a wealth of information on the early history of Chan Buddhism, on the possible influences of this chronicle (School) on the Tibetan, Korean and Japanese Buddhism and

* I am grateful to Acta Orientalia as well as the anonymous referees fo enhancing the readability of this article. All mistakes, should this article have, are mine.

${ }^{1}$ The complete or nearly complete texts of the Lidai fabao ji are: P.2125, S.516, P.3717, and Jinyi 304v (housed by Tianjinshi yishu bowuguan 天津市藝術博物館). The fragments are S.5916, S.1611, S.1776, part of P.3727, Jinyi 103v (a few columns which are largely illegible), F.261 (The Institute of Oriental Studies of the Russian Academy of Sciences, St. Petersburg), the Ishii Sekisuiken 石井積翠軒文庫 copy (in Japan), and Ch.3934r (at the Staatsbibliothek in Berlin) which contains four columns. In addition, there is one more fragment, S.11014. But it only records the title, Lidai fabao ji. Except for Ch.3934r which was found in Turfan during the German expeditions of 1902-1914, all other manuscripts were discovered in Dunhuang. For this list of sources, see also Wendi L. Adamek's monograph which grows out of her $\mathrm{PhD}$ dissertation, The Mystique of Transmission: On an Early Chan History and its Contexts (2007, p. 408, note 9). 
as well on the contemporaneous religious milieus such as the attitudes toward Manicheans, Christians and Zoroastrians. ${ }^{2}$

The discovery, composition, contents, importance as well as the current understanding of these manuscripts can be gleaned from the following paragraph written by Wendi L. Adamek (2011, p. 3):

The Lidai fabao ji was long considered lost. It was resurrected from among manuscripts accidentally discovered in 1900 in a hidden cache [Cave 17] at the Mogao caves, near the Silk Road oasis of Dunhuang. By then there were few other traces of Chan Master Wuzhu [無住] (714774) and his group, the Bao Tang (Protect the Tang Dynasty) school of Jiannan (Sichuan). The text was probably compiled within a few years after Wuzhu's death, which makes it one of the most immediate accounts of a Zen master in early Chan/Zen history. Its obscurity also means that it is one of the least reworked. The Lidai fabao ji gives us remarkably lively glimpses of Wuzhu and his interlocutors, both adoring and hostile. It also gives us a window into a world of complex religious and cultural battles, many of which continued to resonate today.

As attested by this quotation, there is no doubt that many scholars see the extant fragments as the original Tang texts of the Lidai fabao ji, or as sources of "the least reworked", and confidently use them to analyse the early Chan Buddhism. While I entirely agree that there is a Tang source that was entitled 'Lidai fabao ji', it must be pointed out that most known manuscripts, long or short, are fragments that have been reworked between 907, when the Tang dynasty collapsed, and the early 11th century when the Dunhuang Cave 17 was sealed off.

First of all, the Chinese scholar Rong Xinjiang has already observed that some manuscripts might be post-Tang copies of the Lidai fabao ji. For example, according to him (1997, p. 236), S.1776 and S.1611 were made by the same hand after 907 because the verso of S.1776 bears the year 958, and P.3727, given the date 955 assigned to its verso, also must have been produced in the middle of the 10th century. Furthermore, the Ishii Sekisuiken copy, Rong Xinjiang (2010, p. 156) claims, can be seen as an abridgment of S.516, which, as to be argued, was made after 907.

Secondly, two interesting phrases, although they have not received any scholarly attention, clearly indicate that most manuscripts were made after 907 . More precisely, the sources were reworked texts which contain redactions by post-Tang hands. The first phrase is Tangchao 唐朝 (the Tang dynasty), which can be found in P.3717, S.1776, Jinyi 304 as well as in the texts edited by Adamek (2007, pp. 316, 319, 320) who mainly relies on P.2125 and S.516. In the imperial China, such a phrase was very rarely used at a time when that dynasty was still in power. Few contemporaneous sources have ever placed the character chao 朝 (dynasty) after the name of the ruling dynasty. Almost without exception, the name of the dynasty would have been preceded

\footnotetext{
Zikai (2000).

${ }^{2}$ For a nice survey of the literature poured out during the past 100 years or so, see Zhang
} 
by some laudatory character like $d a$ 大 (big) and ju 巨 (huge) - in this case, da Tang 大唐 (big Tang). If this were not the case, the dynasty's name would have been replaced by such phrases as guochao 國朝 and wochao 我朝. Of course, the dynasty's name could also be used alone - in this case, Tang (唐), which can be found in the following edict issued in 705. I am not aware of a single Tang text that has ever employed the phrase Tangchao.

The second phrase is Tangchao Zetian shi 唐朝則天時 (Zetian's reign of the Tang dynasty), which occurs in S.516, Jinyi 304v and F.261, the last of which has been transcribed by Rong Xinjiang (1997, p. 239, Column 33). Compared with the first phrase, this phrase was much more rarely used before 907, and its use sheds more definitive light on the post-Tang redactions. 'Zetian's reign' refers to the period during which the only female, Empress Wu Zetian 武則天, ruled China with the title huangdi 皇帝 (emperor). In 690, she ascended the Chinese throne and changed the dynasty's name from Tang to Zhou 周. She effectively held power until 705 when she was overthrown by a coup d'état. After 705 when the name of the dynasty was changed from Zhou back to Tang, her reign was occasionally designated da Zhou 大周 (big Zhou), and she was often referred to as Zetian dasheng huangdi 則天大聖 皇帝 (Zetian, the greatly sagacious emperor). Both terms are used, for instance, in Jiwei shewen 即位赦文, an edict by Tang Zhongzong 唐中宗 (2. 638-684, 705710) soon after his mother Empress Wu abdicated the throne and he was restored to power (Dong Gao 1819/1983, pp. 206-207, my emphasis):

Zetian, the greatly sagacious emperor, had true wisdom and accomplished virtues. [...] As our enterprises have been reformed, the matters will also be reorganised. It is proper to change [our country's designation] from $\underline{d a Z h o u}$ to Tang. 則天大聖皇帝亶聰成德 [...... 業既惟 新。事宜更始。可改大周為唐。

In fact, a post-705 source very rarely employs the phrase 'Zetian's reign of the Tang dynasty' to refer to her fifteen-year reign. All the later Tang emperors showed great reverences for Empress Wu probably because of the all-pervading influence of ancestor worship. More often than not, she was known as Tianhou 天后 (Heavenly Empress). In 837 when the Tang court renounced the orthographic forms promulgated by Empress Wu Zetian, Tang Wenzong 唐文宗 (r. 827-840), for instance, employed the phrase Tianhou (Wang Qinruo 1013/1989, p. 337, my emphasis):

In the tenth month of the second year [of the Kaicheng reign], it is ordered that the twelve characters created by the Heavenly Empress [Empress $\mathrm{Wu}$ ] shall be abandoned and restored to their original forms. [開 成]二年十月詔日天后所撰十二 字並卻書其本字。

In other words, the above two phrases are more often seen in the sources made after the collapse of the Tang court. The known manuscripts of the Lidai fabao ji cannot be seen as the 8th-century sources. They are not even the later copies of the original Tang texts. The majority, especially the four relatively complete ones (P.2125, S.516, P.3717, and Jinyi 304v), have been reworked or redacted by post-Tang hands 
who were probably sympathisers of Chan Buddhism. Although we do not know the degree of redaction and thereby cannot rule out the possibility that the surviving manuscripts do contain some portions of the original Tang words, the 8th-century texts have not come down to us, and the original Tang version of the Lidai fabao ji remains elusive to date.

Nonetheless, the questioning documents, as suggested by post-Tang locutions, can be dated much later than previously thought. This makes them less trustworthy than commonly assumed. Extreme caution should be exercised if we are to use these extant manuscripts as the Tang sources.

\section{References}

Adamek, Wendi L. (2007): The Mystique of Transmission: On an Early Chan History and its Contexts. New York, Columbia University Press.

Adamek, Wendi L. (2011): The Teachings of Master Wushu. New York, Columbia University Press.

Dong Gao 董誥 (1819/1983): Quantangwen《全唐文》[Collections of Tang essays]. Beijing, Zhonghua shuju.

Rong Xinjiang 榮新江 (1997): Dunhuangben chanzong dengshi canjuan shiyi 敦煌本禪宗燈史殘 卷拾遺. In: Bai Huawen et al. 白化文等 (eds): Zhou Shaoliang xiansheng xinkai jiuzhi qingshou wenji 《周紹良先生欣開九秩慶壽文集》 [Papers on Prof. Zhou Shaoliang's 90th birthday]. Beijing, Zhonghua shuju.

Rong Xinjiang 榮新江 (2010): Bianwei yu cunzhen: Dunhuangxue lunji 《辨偽與存真: 敦煌學論 集》 [Discriminate the false and uphold the true: essays on Dunhuang studies]. Shanghai, Shanghai guji chubanshe.

Wang Qinruo 王欽若 (1013/1989): Cefu yuangui 《冊府元龜》 [References for administration]. Beijing, Zhonghua shuju.

Zhang Zikai 張子開 (2000): Dunhuang xieben 'Lidai fabao ji' yanjiu shuping 敦煌寫本《歷代法 筫記》研究述評 [Studies of the Dunhuang manuscripts, Lidai fabaoji: a survey]. Zhongguoshi yanjiu dongtai 《中國史研究動態》No. 2, pp. 11-19. 